\title{
Observations on the pathology of the Moebius syndrome
}

\author{
SAMUEL E. PITNER, JAMES E. EDWARDS, ${ }^{1}$ AND WILliAM F. MCCORMICK
}

From the Section of Neurology, Department of Pediatrics, and the Section of Neuropathology, Department of $\overrightarrow{\overrightarrow{\vec{S}}}$ Pathology, of the University of Tennessee and the City of Memphis Hospitals, Memphis, Tennessee, U.S.A.

The first report of the congenital facial diplegia syndrome, or Moebius syndrome, was that of Graefe (1880). Moebius reported cases in 1888 and 1892 and reviewed the prior case reports, thus gaining eponymic distinction. Since that time, some authors have broadened the definition of the Moebius syndrome, as for example, Henderson (1939), who considered some cases of congenital unilateral facial palsy to belong to the syndrome. We would agree with the definition of Van Allen and Blodi (1960) that the syndrome consists of varying degrees of facial paresis, usually a facial diplegia, associated with an apparent paralysis of lateral gaze. This is frequently associated with paresis of other muscles supplied by the motor cranial nerves, and with other deformities such as micrognathia, talipes, and the congenital absence of various muscles, particularly the pectoral group. The condition is congenital and not progressive; the clinical features have been reviewed in detail by Henderson (1939). Cases of congenital unilateral facial paralysis without other facial muscular weakness or musculo-skeletal anomalies (Richter, 1958 and 1960) and a case of congenital bilateral sixth nerve palsy (Phillips, Dirion, and Graves, 1932) possibly represent a forme fruste of the syndrome. The syndrome of congenital flaccid bulbar palsy (Graham, 1964) probably represents essentially the same disorder with prominent bulbar symptoms. Some cases of congenital laryngeal abductor paralysis could represent a variant of the Moebius syndrome, as pointed out by Plott (1964).

Only three histological examinations of undisputed cases of the complete syndrome could be found (Heubner, 1900; Spatz and Ullrich, 1931; Wallis, 1960); the last author did not report the pathological findings in detail. Two other pathological reports (Fényes, 1937; Riggs, 1958) have been challenged by some (Henderson, 1939; Richter, 1958) as representing intrapartum brain-stem

'Present address: Department of Psychiatry, Washington University, St. Louis, Missouri.

${ }^{2}$ Present address: Section of Neuropathology, Department of Pathology, State University of Iowa, Iowa City, Iowa. haemorrhage rather than a true congenital anomaly. $\frac{\overline{\bar{D}}}{\bar{D}}$ Henderson (1939) and Richter (1960) also believe that $\stackrel{\mathbb{Q}}{\complement}$ a case reported by Rainy and Fowler (1903) was \% probably due to trauma to both facial nerves by $\vec{\circ}$ obstetrical forceps. Pathological examination in the above cases, except those of Heubner (1900) and of $\vec{\omega}$ Rainy and Fowler (1903), was limited to the brain; the peripheral portion of the seventh nerve and its muscles were not examined. Of the 'partial' forms of the syndrome, the central nervous system pathology $\infty$ in a case of congenital bilateral abducens palsp $\dot{\omega}$ has been reported (Phillips et al., 1932) and the neuropathological findings in a case of congenit@ unilateral facial paralysis not associated with othe defects has also been described (Richter, 1958 aw 1960). In none of these reports have the involved cranial nerves (when present) been examined in their extracranial courses, nor are any authors besides Heubner (1900) and Rainy and Fowler (1900 whose case probably does not represent a trüe $\mathrm{T}$ congenital defect, known to have examined any of the paralytic musculature. Isolated examinations of involved facial or extra-ocular muscles by biopsies have been reported by several authors (Richards, $\stackrel{\otimes}{\not}$ 1953; Yasuna and Schlezinger, 1955; Reed and $\stackrel{\circ}{\complement}$ Grant, 1957; Van Allen and Blodi, 1960; and $\underset{\Rightarrow}{\Rightarrow}$ Graham, 1964). These authors had no opportunity $\frac{0}{3}$ to examine the brain.

The purpose of this report is to present the pathological findings in the brain, facial nerves, and involved facial muscles of an infant with the Moebius syndrome, and to comment on the speculations that have been put forward concerning its aetiology. To 3 . our knowledge, this is the only case of the Moebius syndrome in which all of the above structures have $\frac{}{3}$ been examined.

\section{CASE REPORT}

This white male infant was first seen at 30 hours of age because of facial diplegia and poor feeding. He was the $\mathrm{G}$ third child of a 22-year-old mother. Pregnancy had been $\mathrm{N}$ complicated by mild vomiting throughout, and by mild $N$ pedal oedema in the third trimester. Labour and delivery 
were uneventful. The child had a birth weight of $6 \mathrm{lb}$. $10 \frac{3}{4} \mathrm{oz}$., and was described as having a prompt, although not vigorous, cry. A right facial paralysis had been noted by the obstetrician at the time of delivery. Initial feedings had been offered at 12 hours of age and were taken poorly. There was no family history of any similar condition.

General physical examination revealed mild micrognathia and an increased antero-posterior diameter of the chest without definite evidence of emphysema or chest wall deformity. There was no evidence of trauma. No musculo-skeletal anomalies were found; all somatic muscle groups were thought to be normal. On the initial and subsequent neurological examinations the following findings were present: facial diplegia, most marked on the right side; inability to abduct either eye beyond the midline, with the other ocular movements intact; normal pupillary responses and fundi; equivocally decreased sensation to pin prick over the right face and a consistently absent right corneal reflex; bilateral decrease of palatal elevation on gagging; bilateral decrease in the strength of the masseter muscles; and atrophy of the right side of the tongue, without fasciculation, and with deviation to the right on protrusion. Function of the other cranial nerves was intact and the remainder of the neurological examination was normal.

Routine blood counts and urine analyses were normal. Radiographs of the skull were normal, but those of the chest showed bilateral pneumonitis, which did not clear completely throughout the infant's hospital course. Lumbar punctures and subdural taps were normal. Electromyography and muscle biopsy were planned, but could not be carried out due to the moribund condition of the patient.

The hospital course was one of progressive deterioration, marked by recurrent aspiration pneumonia. This occurred in spite of a gastrostomy for feeding (done at 20 days of age), postural drainage, continuous nasopharyngeal suction, and appropriate antibiotic therapy. Continuous oxygen therapy was required throughout the

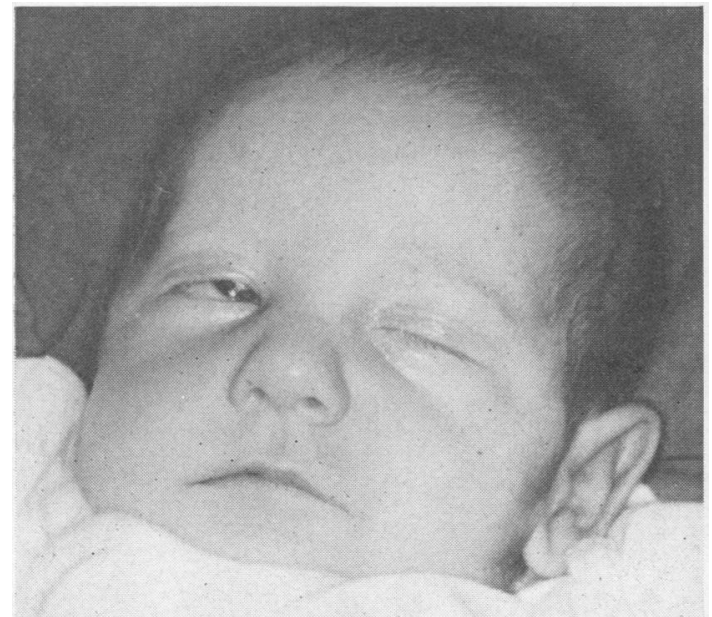

FIG. 1. Photograph of the patient (asleep) at 1 month of age. patient's life to prevent cyanosis. The infant succumbed to aspiration pneumonia at 48 days of age. His appearance at one month of age is shown in Figure 1.

NECROPSY The general necropsy was performed 16 hours after death. Dissection of the facial musculature and the removal of the petrous portion of the temporal bones were done after embalming, and approximately 30 hours after death.

The only significant finding, either grossly or microscopically, outside of the brain, middle and inner ears, and facial musculature was in the respiratory system

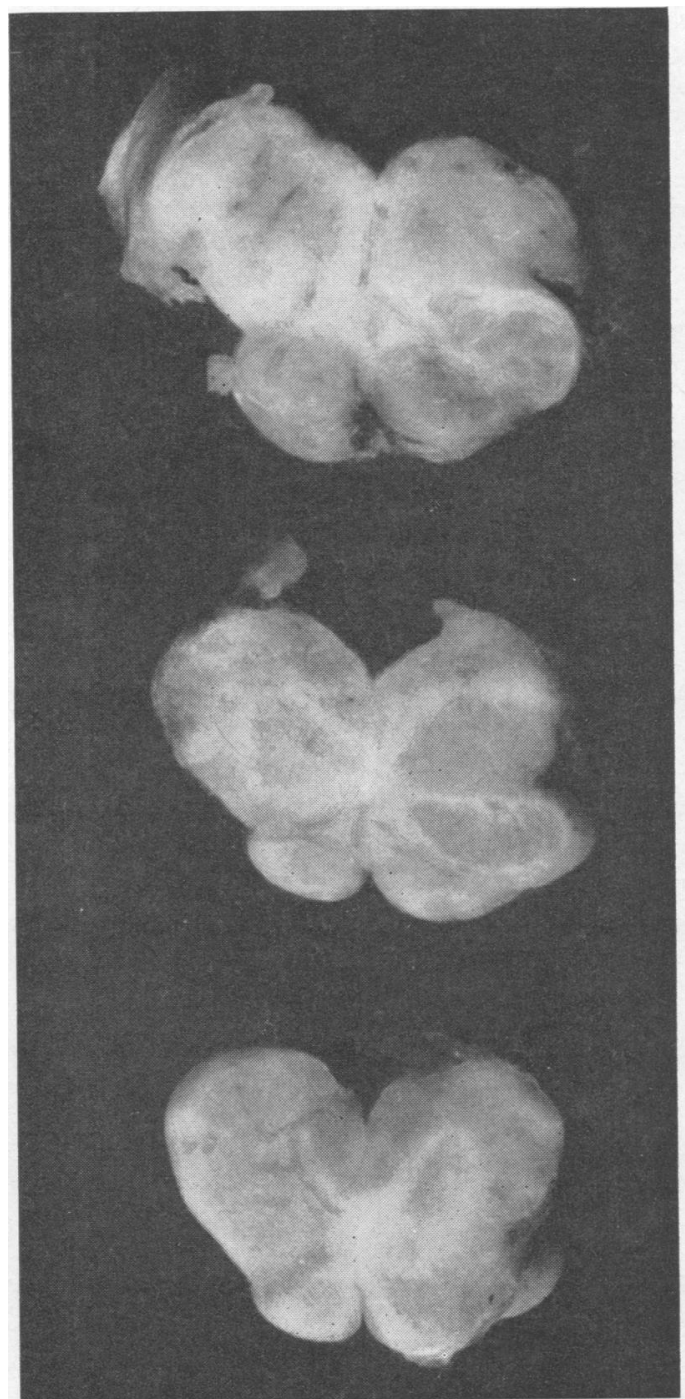

FIG. 2. Gross section of the brain-stem, showing the asymmetry of the two sides, the indistinct olive on the left, and the smaller olivary prominence on that side $(\times 4)$. 
where bilateral aspiration bronchopneumonia was present. Multiple samples of somatic muscles and peripheral nerves were normal. No description of the remainder of the organs is deemed necessary, except to note that no malformations were found.

The petrous portions of the temporal bones were removed en bloc and decalcified in $5 \%$ formic acid. The decalcified blocks were cut at $3 \mathrm{~mm}$. intervals and subserially sectioned following double embedding in celloidin and paraffin wax. The middle ears and mastoid air cells were free of exudate; the internal acoustic meati were normal bilaterally.

Dissection of the face after embalming revealed a relative increase in subcutaneous fat and an almost total absence of muscle; tissue recognizable as muscle was found only in the orbicularis oris, the buccinator, and the zygomaticus. The great majority of the facial muscles could not be identified. The dissection of the face was largely limited to the right side, but the incomplete dissection of the left side also revealed little recognizable muscle. Both eyes were removed and appeared normal grossly, as did their attached muscles. Hemi-atrophy of the tongue was confirmed.

The brain was of normal size for an infant 7 weeks of age. The cerebral hemispheres were symmetrical and the $\bar{Z}$ gyri and sulci were of normal size, shape, and distribution. The leptomeninges were thin and transparent throughout; $\overline{\bar{O}}$ no haemorrhage or exudate was present in the sub-e arachnoid space. The vessels of the circle of Willis were free of abnormalities. There were no cerebral hernias. $\square$ The only abnormalities on gross examination were in the cerebellum and brain-stem, where it was noted that the $\frac{\hat{\rho}}{\partial}$ left olivary prominence was missing (Fig. 2); there was also moderate hypoplasia of the right cerebellar hemisphere, maximal in the ansiform lobule and biventer (Fig. 3). All of the cranial nerves could be identified on the gross specimen and appeared to be normal.

Serial sections of the cerebral hemispheres at $0.5 \mathrm{~cm}$. intervals revealed moderate congestion of the vessels in $\overline{\bar{\omega}}$ the centrum semiovale, a small cavum septi pellucidi, $\vec{\Phi}$ and no abnormalities of the ventricles or basal ganglia. 2 Sections of the brain-stem at $3 \mathrm{~mm}$. intervals showed almost complete absence of the left inferior olivary nucleus. $\rightarrow$ No abnormalities could be seen grossly in the mesence-? phalon or pons. The aqueduct of Sylvius and the fourth $\vec{\overrightarrow{ }}$ ventricle were normal. Sections of the cerebellum at $4 \mathrm{~mm}$. intervals revealed microgyria of the right hemispheric folia with no apparent involvement of the vermis. The

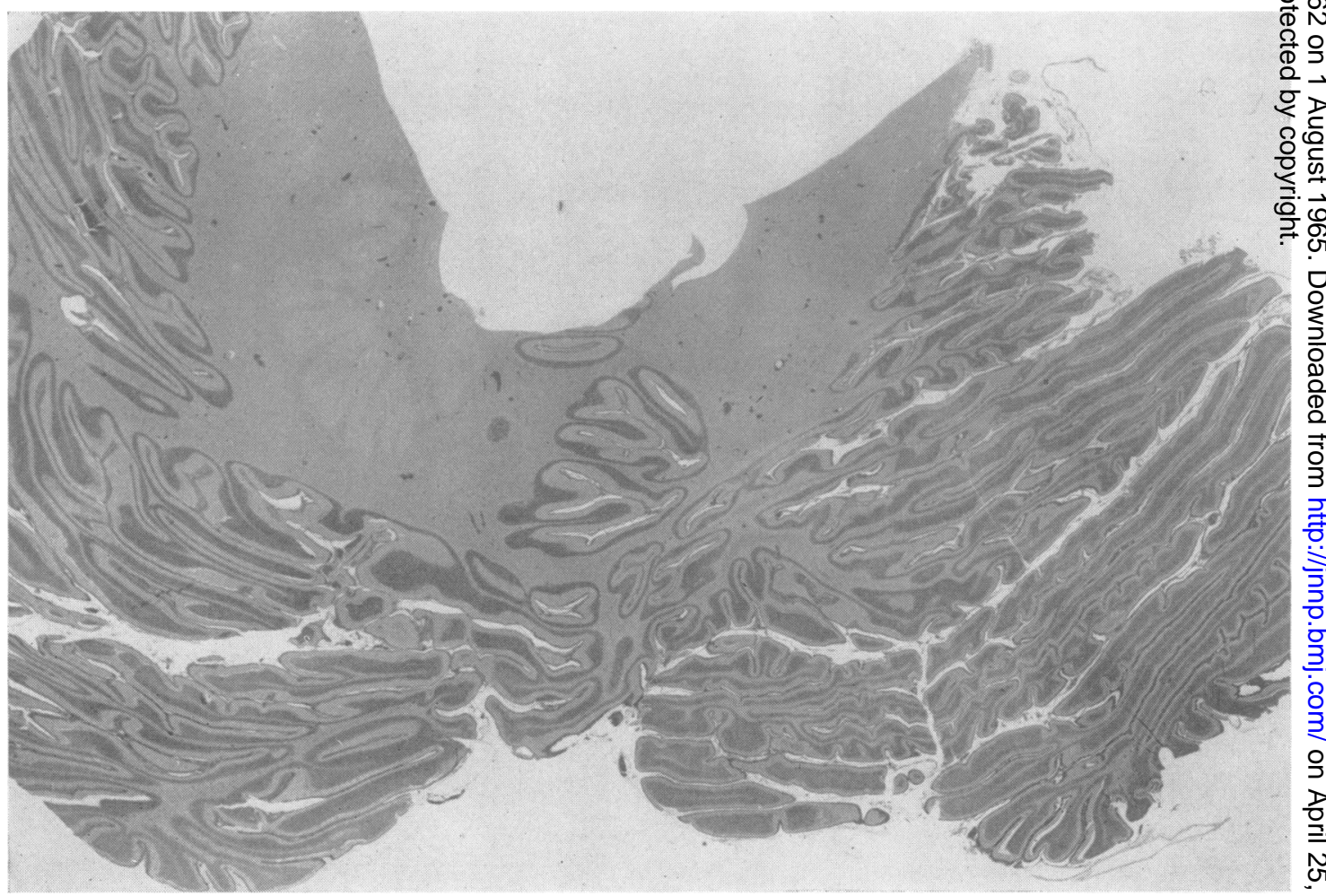

FIG. 3. A low-power view of the cerebellum showing the presence of polymicrogyria on the right, and the absence of the ipsilateral dentate nucleus (haematoxylin and eosin $\times 2$ ). 
right dentate nucleus was very small and indistinct, and there was less conspicuous reduction in size of the right emboliform nucleus (Fig. 3).

The gross neuropathological diagnosis was congenital hypoplasia of the cerebellum and facial musculature.

MICROSCOPIC Multiple sections from the cerebral hemispheres (right and left superior frontal gyri, right and left basal ganglia, left calcarine cortex, and three coronal sections of the cerebri), stained with haematoxylin and eosin, thionine (Nissl), luxol fast blue-P.A.S.H., phosphotungstic acid-haematoxylin, Weil's and Bodian's stains, were prepared for examination. Numerous neurones in multiple areas were undergoing eosinophilic (anoxic) necrosis, and were most numerous in the superior frontal gyri and in the hippocampal gyri. True sector necrosis was not present. Myelination was normal for an infant of 7 weeks. Marked vascular congestion was present in all sections. Multiple discrete foci of neuroblasts were present about veins in the subependymal plate; these were maximal adjacent to the bodies of the caudate nuclei.

Multiple sections of the cerebellum were taken so as to include both hemispheres, the mid-line nuclei and the vermis (Fig. 3). The same battery of special stains was done on the cerebellum as on the cerebrum. Immaturity, as evidenced by a thick outer granular layer and incompletely myelinated white matter, was noted. Vascular dilatation and congestion was present, as was anoxic necrosis of moderate numbers of Purkinje cells. The neurones of the right dentate nucleus were greatly reduced in number. Moderate astrogliosis was present in the dentate nucleus. Mild to moderate neuronal loss with mild gliosis was present in the adjacent emboliform nucleus. The mid-line nuclei on the left were present in normal numbers. Polymicrogyria was conspicuous in the right hemispheric folia (Fig. 3), while the folia of the vermis and left hemisphere were normal. All layers of the folia in the right hemisphere were abnormal, but paucity of neurons was most marked in the inner granular layer. Gliosis was relatively mild. Myelination of the convolutional and central white matter was more complete on the left than on the right. There was no evidence of an inflammatory process, remote haemorrhage, or active cellular degeneration, other than anoxic, in the cerebellum.

Subserial sections of the mid-brain, pons, and medulla werc examined with the use of the special stains. The abnormalities consisted of an almost complete absence of the inferior olivary nucleus on the left and a moderate decrease in the prominence of the restiform body on the right (Fig. 4); marked hypomyelination and hypoplasia of the right brachium conjunctivum and central tegmental tract in the pontine sections (Fig. 5); and hypomyelination of the right superior colliculus in the mesencephalic sections. All cranial nerve nuclei and fibres appeared well preserved. The facial nuclei were of equal size and

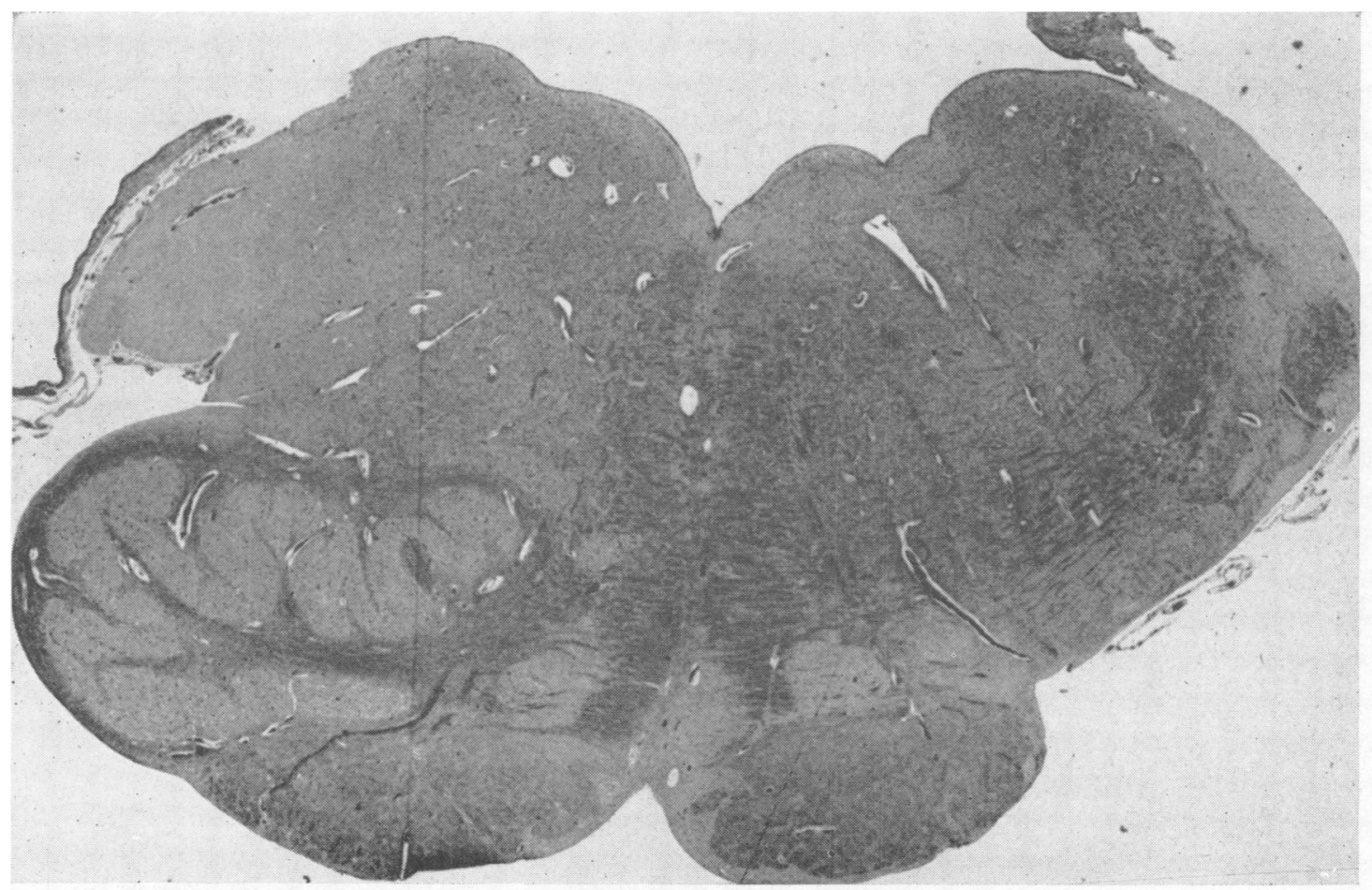

FIG. 4. Weil stain of the rostral medulla, showing the virtual absence of the left olive and the course of the facial nerves $(\times 10)$. 


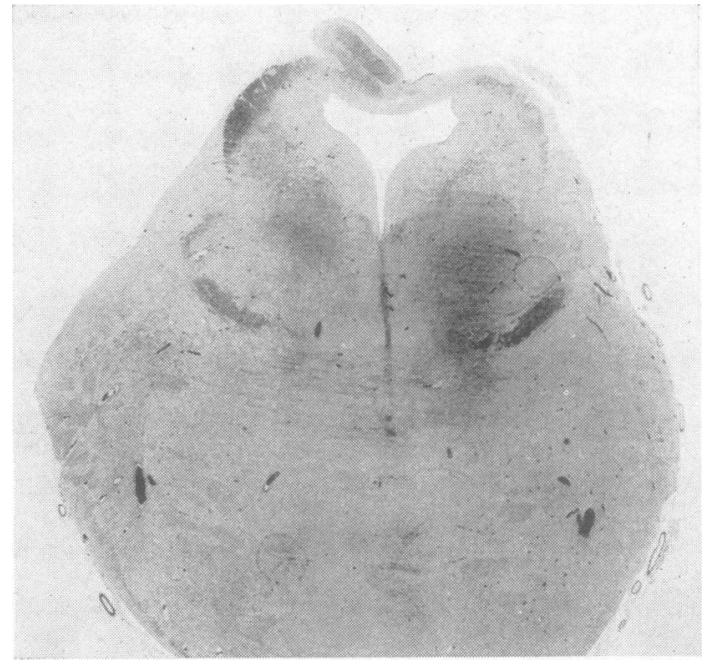

FIG. 5. Section of the pons showing the small and hypomyelinated left brachium conjunctivum (Luxol-Fast Blue) P.A.S.-H., $\times 8$ ).

产

FIG. 6. Nissl stain of the caudal pons showing one of the
facial nuclei $(\times 60)$. These were identical and were not $\stackrel{\overrightarrow{0}}{\overrightarrow{2}}$ thought to show any abnormality.

FIG. 5 .

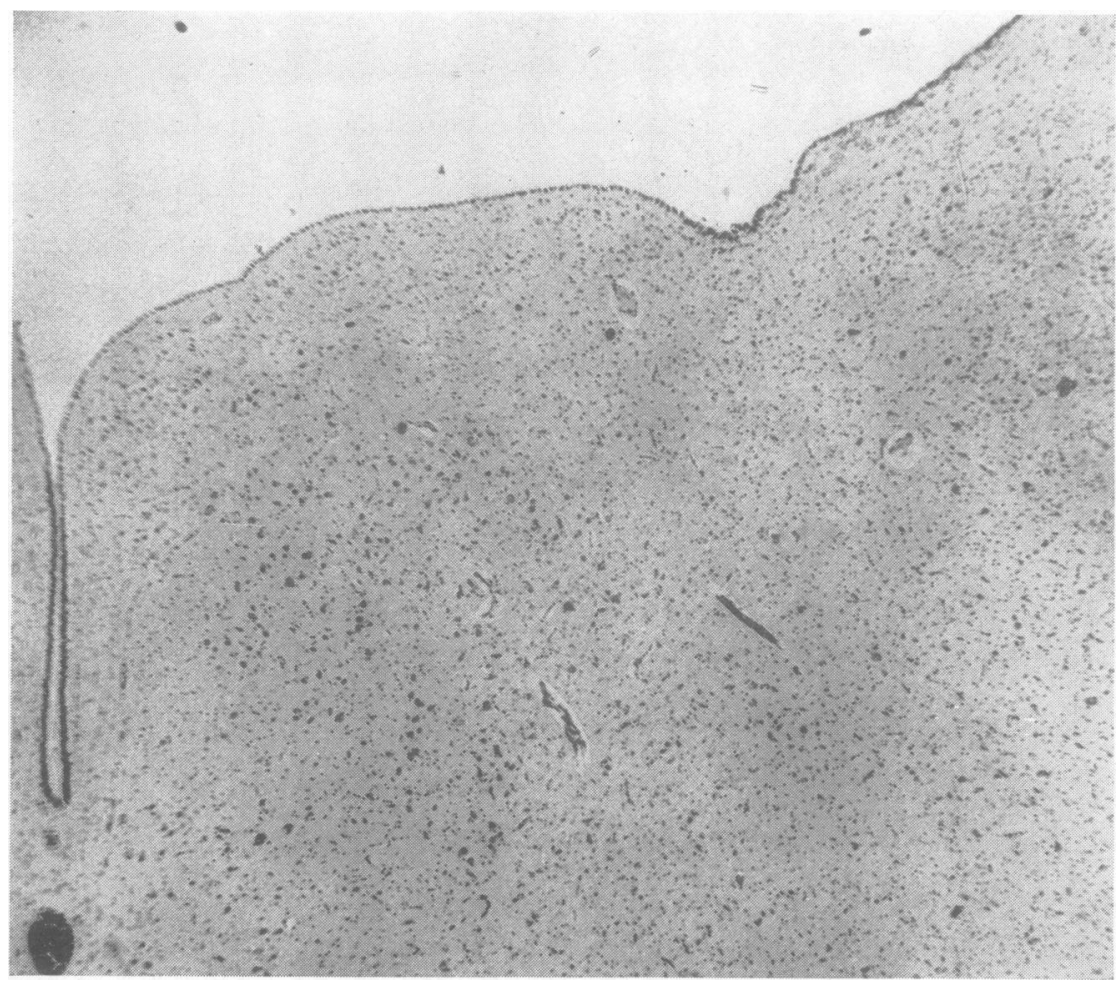

FIG. 6. 


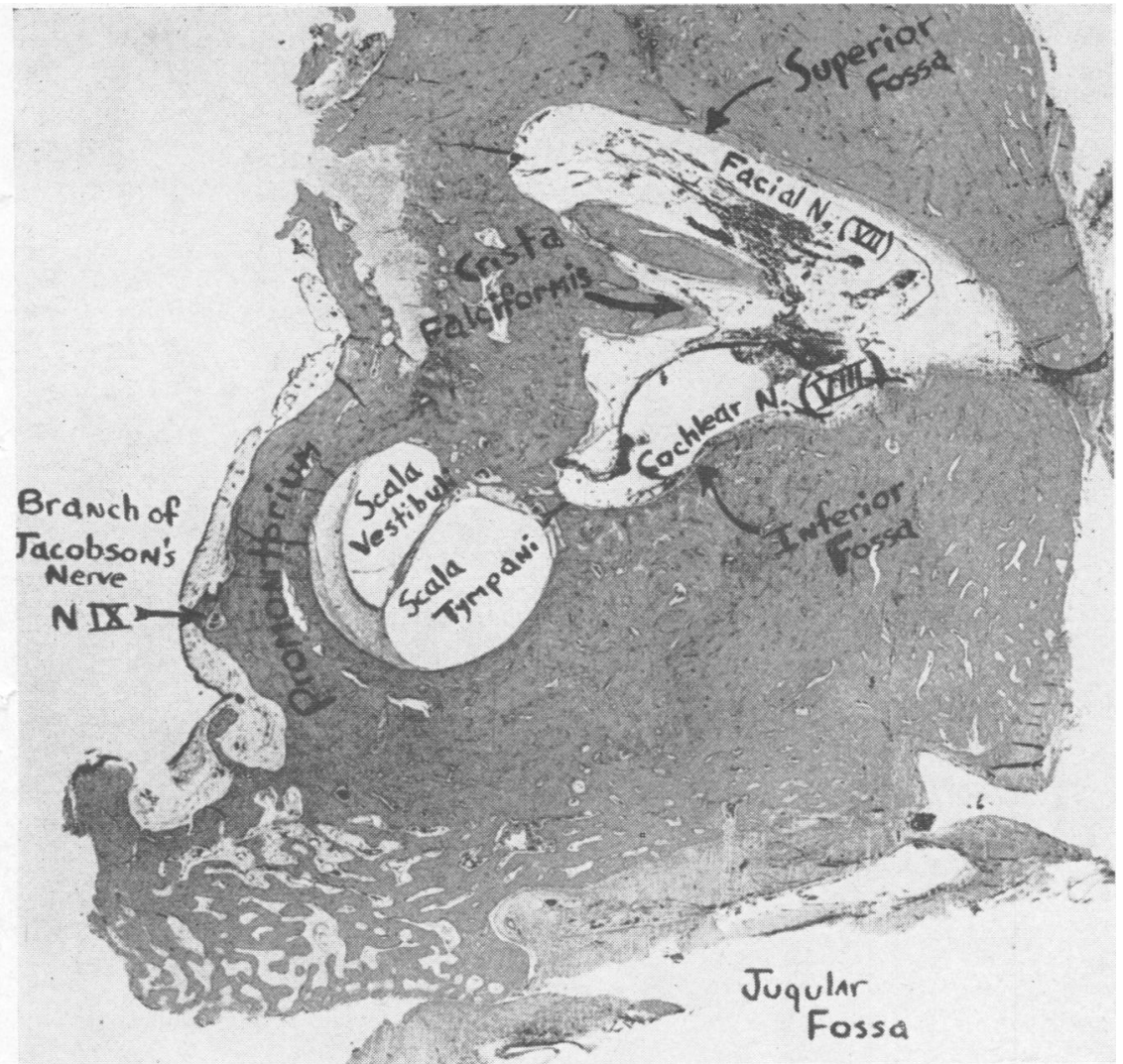

FIG. 7. Section of the inner ear showing components of cranial nerves $V I I, V I I I$, and IX (haematoxylin and eosin, $\times 8)$. These are thought to be normal except for autolytic changes.

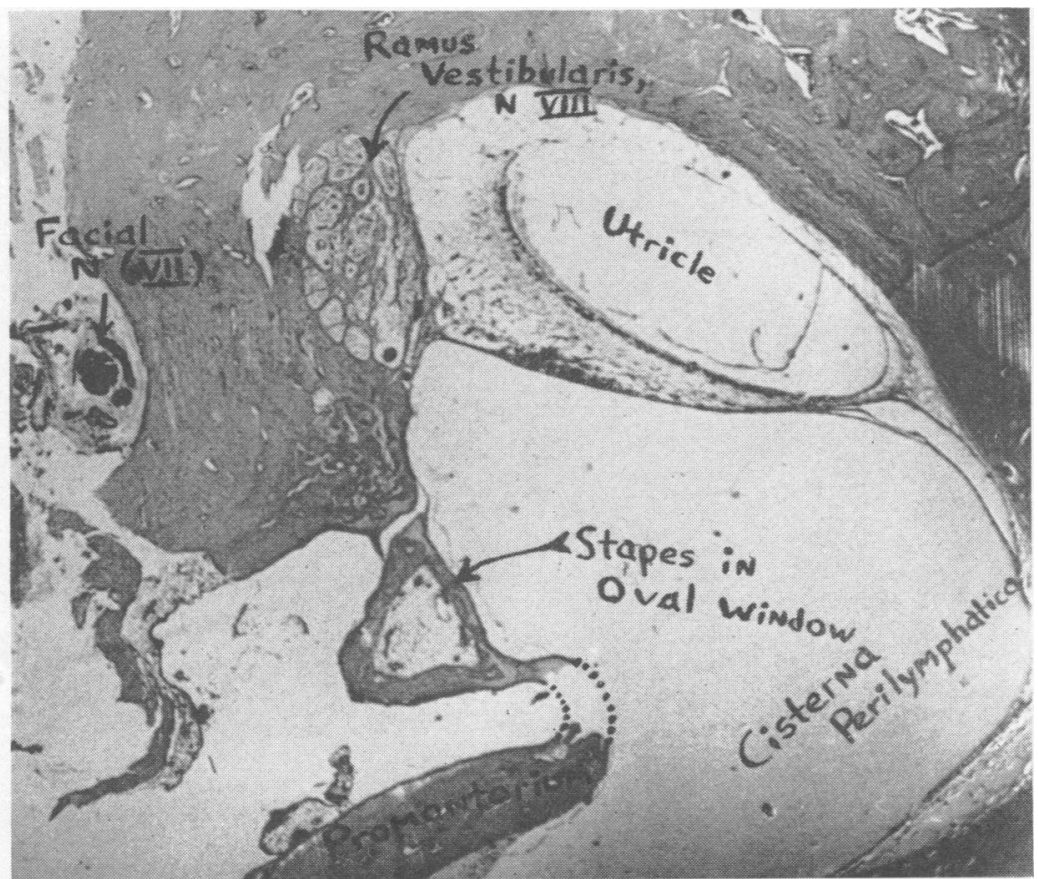

FIG. 8. Inner ear at the level of the oval window, showing portions of cranial nerves VII and VIII (haematoxylin and eosin, $\times 20$ ); incidental otosclerosis is present. 


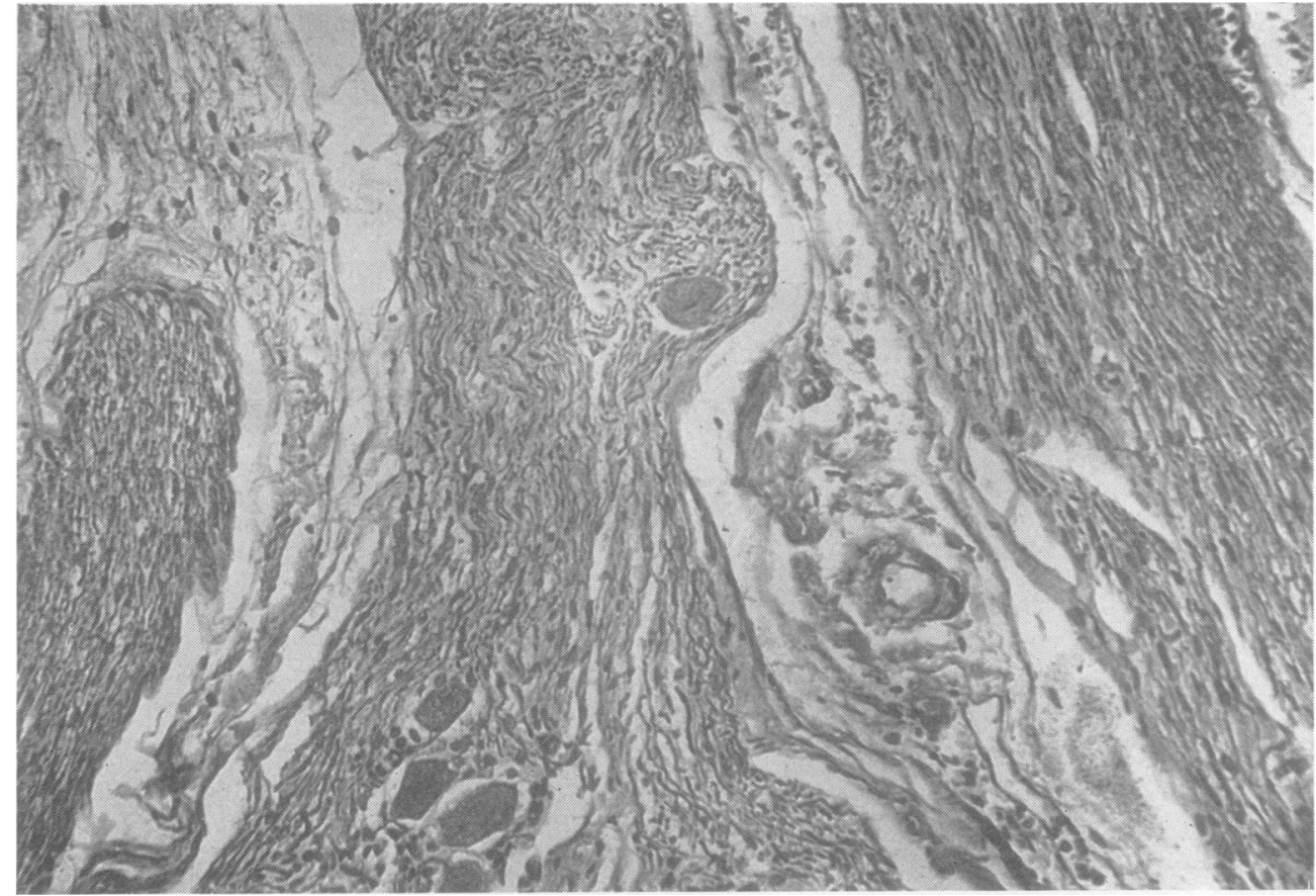

FIG. 9. Section of the right Gasserian ganglion, which is thought to be normal (Bodian, $\times 60$ ).
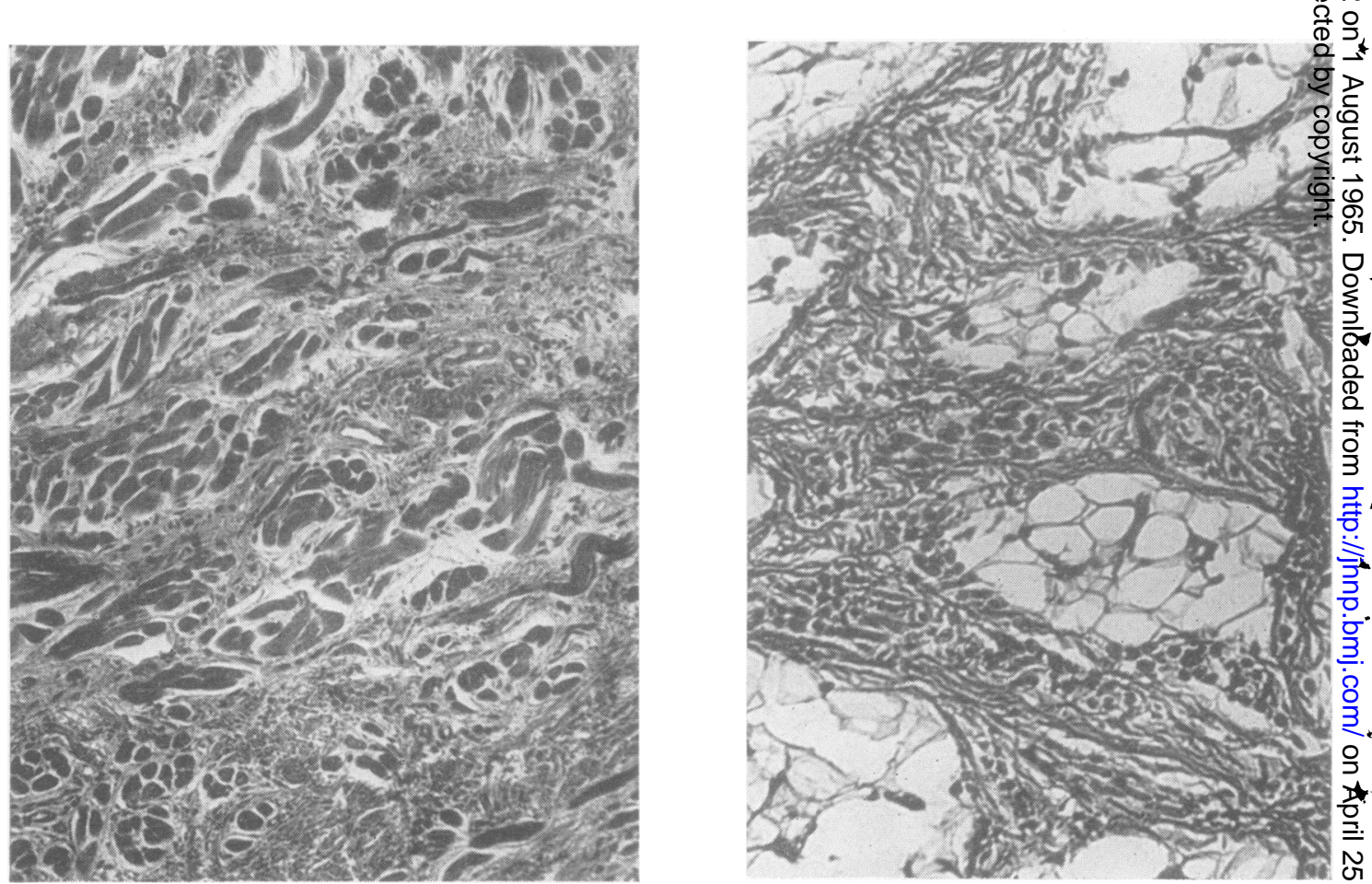

FIGS. 10 AND 11. Muscle from the right buccinator, showing (left) adipose and fibrous 'replacement' of the muscle N (haematoxylin and eosin, $\times 100)$, and (right) a more involved area at a higher power $(\times 200)$. 
cellularity, and were considered to contain normal numbers of neurons (Fig. 6). The individual neurons appeared normal. The facial nerves could be identified in their intraparenchymal course, as well as in the subarachnoid space, and also appeared normal.

Examination of the subseriel sections of the petrous portions of the temporal bones revealed no significant abnormalities and demonstrated the presence of the intraosseous portions of cranial nerves VII, VIII, and IX (Fig. 7). Autolytic and embalming artefacts prevented a detailed evaluation of the fine structure of the facial nerves in the temporal bone, but they appeared normal (Fig. 8). Otosclerosis was an incidental finding on the right 2 side. Sections of the Gasserian ganglia revealed normal structures (Fig. 9). Autolytic changes were moderate in its neurones, but no significant decrease in the number of neurones could be seen. The axons of the trigeminal nerve were intact.

Normal nerve trunks thought to represent the more peripheral branches of the facial nerves were seen passing through the parotid glands in sections of those organs.

Multiple sections of the facial and extraocular muscles were prepared with haematoxylin and eosin, trichrome, phosphotungstic acid-haematoxylin, Bielschowsky's, and Bodian's stains. The extraocular muscles were normal. A decrease in the bulk of the right side of the tongue was apparent, but no definite microscopic changes were found in the muscle fibres. Severe alterations of the facial muscles were present. The primary finding was a decrease in the number of myofibres present, ranging from very severe (Fig. 10) to moderate (Fig. 11). Those myofibres present were generally small, ranging from $4 \mu$ to $30 \mu$ in diameter. Variation in myofibre size was conspicuous, but not to the degree usually seen in an active and progressive dystrophic process. Fine structural analysis of the muscle was not completely satisfactory due to autolytic and embalming artefacts. It appeared from the arrangement of fibrous elements in the sections that some muscle fascicles had formed. Although fibrosis was mild to moderate, adipose 'replacement' of muscle was severe. There was nothing to indicate active degeneration or regeneration of muscle, nor was there any phagocytosis of muscle apparent. Migration of sarcolemmal nuclei was not prominent. The changes did not have the distribution of a typical neurogenic atrophy, and nerve fibres were present among the identifiable muscles and in the adipose tissue. While in the absence of satisfactory motor end plate stains they could not be proven to be motor fibres, it was felt probable that many were. The changes were thought to represent a primary failure of formation, differentiation, or maintenance of the involved muscle, rather than changes secondary to a neuronal dysplasia or degeneration.

The microscopic neuropathological diagnosis was congenital cerebellar hypoplasia with associated changes in the midline cerebellar nuclei, pons, and olives; unilateral otosclerosis; and probable primary dysplasia of the facial muscles.

\section{DISCUSSFON}

Throughout the literature of the Moebius syndrome, most authors, with or without pathological evidence, have speculated concerning the responsible defect. Moebius (1892) thought that the disorder was degenerative in nature (infantiler Kernschwund). In the absence of morphological evidence of degeneration, most later authors have felt that this view was incorrect. The various possible aetiologies outlined by Lennon (1910) have all had their proponents in the subsequent literature. Lennon thought that the defect could be either degenerative or dysplastic, and that it could involve either the brain-stem, the facial nerve in the temporal bone, or the facial musculature. Since that time, as pointed out by Richter (1960), discussion of the syndrome has centred around the question as to whether the disorder is primarily degenerative or dysplastic, and as to the location of the primary defect. The postulated primary defects in the Moebius syndrome, together with their proponents, are summarized in Table I. Most of the evidence favours the dysplastic rather than the degenerative theory of pathogenesis.

TABLE I

POSTULATED DEFECTS IN THE MOEBIUS SYNDROME

\begin{tabular}{|c|c|c|c|}
\hline \multicolumn{3}{|c|}{ Type of Defect } & \multirow{2}{*}{ Author and Year } \\
\hline \multirow{16}{*}{ II } & \multicolumn{2}{|c|}{ Degenerative } & \\
\hline & & Primarily in the brain- & Möbius (1892) \\
\hline & & stem & $\begin{array}{l}\text { Rainy and Fowler (1903) } \\
\text { Fényes (1937) }\end{array}$ \\
\hline & B & Primarily involving the & Marfan and Armand-Delille (1901) \\
\hline & & $\begin{array}{l}\text { cranial nerves outside } \\
\text { the brain-stem }\end{array}$ & \\
\hline & $\mathrm{C}$ & $\begin{array}{l}\text { Primarily involving the } \\
\text { affected muscles }\end{array}$ & \\
\hline & \multicolumn{3}{|c|}{ Dysplastic or Aplastic } \\
\hline & \multirow{4}{*}{\multicolumn{2}{|c|}{$\begin{array}{l}\text { A Primarily in the brain- } \\
\text { stem }\end{array}$}} & Heubner (1900) \\
\hline & & & Spatz and Ullrich (1931) \\
\hline & & & Richter (1960) \\
\hline & & & Van Allen and Blodi (1960) \\
\hline & B & $\begin{array}{l}\text { Primarily involving the } \\
\text { cranial nerves outside } \\
\text { the brain-stem }\end{array}$ & \\
\hline & & $\begin{array}{l}\text { Primarily involving the } \\
\text { affected muscles }\end{array}$ & Neurath (1907) \\
\hline & & & $\begin{array}{l}\text { Lennon (1910) } \\
\text { Richards (1953) }\end{array}$ \\
\hline & & & Evans (1955) \\
\hline & & & Wallis (1960) \\
\hline
\end{tabular}

The static clinical course of the disorder is in itself indirect evidence against a degenerative process, as a degeneration would be expected to continue into post-natal life. No convincing evidence favouring a degenerative process has been produced. Moebius (1892), who first postulated that the disorder was degenerative, had no pathological material. None of the authors supporting this view have had unequivocal histological evidence. Marfan and Armand-Delille (1901) found degenerative changes in the brain-stem in their case of congenital unilateral facial palsy, but these were probably secondary either to entrapment of the facial nerve 
in a malformed temporal bone, or to intra-uterine pressure on the developing facial nerve. The same mechanism in all probability was involved in the case of congenital unilateral facial palsy examined by Neurath (1907). We would agree with Richter (1958; 1960) that the findings reported by Fényes (1937) and Riggs (1958) are possibly the result of intrapartum haemorrhage into the brain-stem, and are not truly representative of the Moebius syndrome. In the case of Rainy and Fowler (1903) degenerative changes were found in the facial nerve nuclei, the genu of the nerves, and the nerves in the subarachnoid space and temporal bone; the small amount of muscle that could be found was described as normal. As pointed out by both Henderson (1939) and Richter (1960), the absence of any impairment other than facial diplegia plus the history of an instrumental delivery with obvious trauma very strongly suggests that the degenerative changes in this case were secondary to trauma to the facial nerves. Degenerative changes have not been reported by any authors who examined an unequivocal case of the complete syndrome (Table II). Human and animal teratology and experimental embryology present no findings to suggest by analogy that the condition could be primarily degenerative. The available evidence thus strongly suggests that the basic defect in the syndrome is dysplastic rather than degenerative in nature.

It is more difficult to determine the site of the primary defect. Two opinions as to the site of malformation have evolved in the literature. One theory holds that the Moebius syndrome is a mesodermal dysplasia involving musculature derived from the

TABLE II

REPORTED NECROPSIES IN CASES OF THE MOEBIUS SYNDROME AND RELATED ISOLATED CONGENITAL PALSIES OF MUSCLES INNERVATED BY CRANIAL NERVES

\begin{tabular}{|c|c|c|c|c|}
\hline \multicolumn{2}{|c|}{ Author and Year } & \multicolumn{3}{|c|}{ Tissue Examined } \\
\hline & & $\begin{array}{l}\text { Central } \\
\text { Nervous } \\
\text { System }\end{array}$ & $\begin{array}{l}\text { Peripheral } \\
\text { Nerve VII }\end{array}$ & $\begin{array}{l}\text { Involved } \\
\text { Muscles }\end{array}$ \\
\hline \multirow[t]{5}{*}{ I } & Classical cases & & & \\
\hline & Heubner (1900) & Yes & Yes & Tongue only \\
\hline & Spatz and Ullrich (1931) & Yes & No & \\
\hline & Wallis (1960) & Yes & Unknown & Unknown \\
\hline & Current case (1965) & Yes & Yes & Yes \\
\hline \multirow[t]{4}{*}{ II } & Disputed cases & & & \\
\hline & Rainy and Fowler (1903) & Yes & Yes & Yes \\
\hline & Fényes (1937) & Yes & & \\
\hline & Riggs (1958) & Yes & Absent & Unknown \\
\hline \multirow[t]{4}{*}{ III } & $\begin{array}{l}\text { Congenital unilateral facial p } \\
\text { Marfan and Armand- }\end{array}$ & aralysis & & \\
\hline & Delille (1901) & Yes & Yes & No \\
\hline & Neurath (1907) & Yes & & No \\
\hline & Richter (1960) & Yes & Absent & No \\
\hline \multirow[t]{2}{*}{ IV } & $\begin{array}{l}\text { Congenital bilateral abducens } \\
\text { Phillips, Dirion, and }\end{array}$ & saralysis & & \\
\hline & Graves (1932) & Yes & - & No \\
\hline
\end{tabular}

branchial arches (and frequently musculature de $Z$ rived from somites) and that any changes found in $\stackrel{\mathbb{C}}{\mathrm{C}}$ the brain-stem are secondary. Lennon (1910), Richards (1953), Evans (1955), and Wallis (1960) seem to be proponents of this view (Table I). The other theory is that the syndrome is the result of an ectodermal dysplasia involving primarily the centrals nervous system, and that any associated musculoskeletal anomalies are either secondary or fortuitous.? Heubner (1900), Spatz and Ullrich (1931), Richter $\Rightarrow$ $(1958 ; 1960)$, and Van Allen and Blodi $(1960) \stackrel{\text { ? }}{+}$ among others, appear to accept this view (Table I). As there is no evidence to suggest that there is dys $-\frac{\bar{c}}{\bar{c}} \mathrm{~d}$ plasia of the facial nerve in its course beyond the $\frac{D}{\widetilde{T}}$. brain-stem, or in its termination at the motor endo plates, most authors have supported one or the otheres of these divergent views.

A theory of the pathogenesis of the Moebius. syndrome that invokes both ectodermal and meso- $\vec{\omega}$ dermal involvement has been put forward by Ullrich (1949). He described an entity which he called 'the asymmetric form of status Bonnevie-Ullrich', many? cases of which fulfil our criteria for the diagnosis of 0 the Moebius syndrome in that they show multipte pareses of muscles innervated by cranial nereso together with limb deformities. He based his theopyo on the experiments of Bonnevie (1934), who studigd the evolution of genetically determined limb and exp deformities in an inbred strain of experimental miç and concluded that these deformities were caused $8 y \frac{c}{\infty}$ overproduction of spinal fluid resulting in the forma $-?$ tion of subcutaneous cysts over the myelencephalo $\overrightarrow{0} ; \vec{\oplus}$ these cysts subsequently migrated to the eye and limb anlage and produced various deformities by pressure. While the limb deformities were similar to those described in the Moebius syndrome, the eye anomalies at maturity consisted of absent or atrophic eyelids, corneal opacity, cataracts, or microphthal- $\frac{\mathrm{D}}{2}$ mia; the facial or extraocular musculature was not $\underset{\Rightarrow}{\Rightarrow}$ specifically involved. Not only was the condition $\frac{0}{3}$ dissimilar to the Moebius syndrome, but many embryologists thought the mode of formation of the blebs and their subsequent migration to be insufficiently proven (Grüneberg, 1952). However, Bonnevie's work, with the addition of the suggestion? that pressure on the floor of the fourth ventricle 3 from the overproduction of spinal fluid could compress the developing facial and abducens nuclei $\frac{O}{3}$ and thus cause facial diplegia and paresis of lateral gaze, was used by Ullrich (1949) to explain the occur-? rence of cranial nerve palsies and limb deformities Although it has been suggested that some portions of this hypothesis could be applicable to the Moebius syndrome (Evans, 1955), we consider it to be unproven in mice much less in man, and would concur with Van Allen and Blodi (1960) and Adams, $\omega$ 
Denny-Brown, and Pearson (1962) that it lacks credibility.

However, the possibility that the syndrome is the result of involvement of both mesoderm and ectoderm by an unknown factor or factors operating early in embryogenesis cannot be ruled out. Finally, it must be acknowledged that the complex relationship of the developing neurone to its peripheral field is incompletely understood, even in the normal organism (Hamburger and Levi-Montalcini, 1950), and that any conclusion as to pathogenesis that is based on morphological changes in the mature organism, in view of the present knowledge of neuroembryology, must remain tentative. With these limitations in mind, it seems worthwhile to review the evidence on which the mesodermal (peripheral) and ectodermal (central) theories of pathogenesis are based.

THE CASE FOR THE MESODERMAL (PERIPHERAL) THEORY The case for a primary mesodermal defect was first stated by Lennon (1910). The frequent association of musculo-skeletal defects, such as absent muscles, club feet, syndactly, and other presumably mesodermal abnormalities, is the mainstay of this argument (Evans, 1955). Congenital facial diplegia not associated with apparent extraocular palsies does occur in dystrophia myotonica (Parker, 1963), thus demonstrating that at least this portion of the syndrome can have a myopathic basis in certain other disorders. Other clinical arguments that have been advanced for a primary mesodermal defect such as absence of sensory change, the distribution of the facial weakness, and the absence of facial sagging (Richards, 1953) do not appear to be valid, as pointed out by Sprofkin and Hillman (1956). Laboratory evidence supporting this view is limited to altered creatine and creatinine metabolism suggestive of a muscular defect, as reported by Wallis (1960). However, some authors, notably Yasuna and Schlezinger (1955), reported normal creatine and creatinine levels. We are unable to find any reports of electromyographic examinations that convincingly point to a myopathic origin. Pathological studies that would tend to support this point of view are those of Wallis (1960) in which no abnormality was found in the brain, and the current case, in which the abnormality in the brain was an apparently unrelated hemi-dysplasia of the cerebellum, with the cranial nerve nuclei intact. It is not known whether muscles were examined in the former case; in the present case the appearance of those muscles that could be identified was somewhat more suggestive of a myogenic origin than a neurogenic origin. Most of the cases in which muscle examinations have been done were limited to biopsy speci- mens, which have been quite inconclusive. Richards (1953) obtained biopsies in three cases, but the reported 'absence of muscles' in the biopsy specimens does not really support either view. Fragments of extraocular muscle were examined microscopically by Yasuna and Schlezinger (1955) and by Reed and Grant (1957). In the former case a resected lateral rectus muscle was reported as showing equivocal neurogenic atrophy. In the latter case, a resected lateral rectus was reported as consisting only of dense fibrous tissue resembling tendon or fascia, without any muscle fibres present. In contrast,Van Allen and Blodi (1960) reported muscle fragments from the levator palpebrae and the lateral rectus as being histologically normal. A biopsy of an involved muscle (site not specified) suggested to Graham (1964) that a primary developmental defect of muscle was present in his case. Thus, some of the conflicting clinical and pathological evidence does lend support to the theory of a mesodermal origin of the defect.

Evidence from human teratology is also conflicting. In the majority of cases of congenital absence of muscles there has been no associated dysplasia of neurones in the spinal cord (Bing, 1902). There are reports of cases with absent muscles and intact spinal cords, and reports of cases with intact muscles and absent spinal cords; as Zelená (1962) states, the evidence from human teratology regarding the interrelationship of the developing motor neurone and its muscle is inconclusive.

Some support for the mesodermal theory of pathogenesis derives from experimental neuroembryology. It has been shown in amphibian and chick embryos that excision of a limb bud before it receives its innervation results in a lessened number of motor cells in the appropriate cord segment at maturity (Hamburger and Levi-Montalcini, 1950). This same phenomenon has been demonstrated in the brain-stem of the chick embryo by Dunnebacke (1953). She excised the primordium of the superior oblique muscle before its innervation, and found that the number of motor neurones in the trochlear mucleus at term was markedly reduced, and that many of those that were present were unusually small. This experimental work would tend to support the theory of a primary mesodermal defect, in that it would offer an explanation for those cases of the Moebius syndrome in which a decreased number of cells has been found in the appropriate motor nuclei of the brain-stem, thus showing that these changes could be secondary to a muscle defect.

THE CASE FOR THE ECTODERMAL (CENTRAL) THEORY The evidence for the theory that holds the syndrome to be due to a primary developmental defect of the 
central nervous system (usually held to be an aplasia of the motor nuclei) has been described by some authors (Van Allen and Blodi, 1960) as 'virtually unassailable'. With the single exception of the necropsy in the case of Wallis (1960), which they probably did not have access to, they are quite correct in stating that no histological examination in an unequivocal case of the Moebius syndrome has revealed a normal brain-stem. There are also some clinical observations that have been cited to support this view, such as the not infrequent association of mental retardation and abnormal electroencephalograms and pneumoencephalograms (Van Allen and Blodi, 1960). While we are aware of no convincing reports of electromyography demonstrating denervation of the facial or extraocular muscles, the same authors used this technique to demonstrate a failure of reciprocal innervation of the extraocular muscles in their case, and postulated that a defect of supranuclear innervation was present. Such a defect cannot be excluded in the current case, as the extraocular muscles and their nuclei were normal on histological examination, and the (normal) hypomyelination of the supranuclear pathways in an infant of 7 weeks would make it impossible to state categorically that these were normal. Although some of the conflicting clinical evidence points to a central nervous system defect, the mainstays of this theory are the reported necropsies in undisputed cases of the Moebius syndrome.

Heubner (1900) reported the pathological findings in a child who undoubtedly had the Moebius syndrome and expired at 20 months of age. Histological examination showed asymmetry of the medulla with hypoplasia of the olive and pyramid on the left side, absence of neurones in the left hypoglossal nucleus, and marked reduction in the number of neurones present in the left spinal accessory nucleus and facial nuclews and both abducens nuclei. The involved cranial nerves were said to be somewhat small. Although no note is made of other muscles, the tongue was examined and was thought to show neurogenic atrophy on the left side. He interpreted these findings as representing primary dysplasia of the brain-stem. Spatz and Ullrich (1931) reported a similar case in which they described either an absence of neurones or a reduction in their number bilaterally in the oculomotor, trochlear, abducens, and facial nuclei, together with dysplasia of the intraparenchymal portions of the associated nerves. Only in the case of Wallis (1960) was the central nervous system reported to be normal. Although no conclusions can be drawn from the disputed cases (Table II), the partial forms are of some interest. The case of congenital unilateral facial palsy reported by Richter $(1958 ; 1960)$ showed a reduction in the number of neurones in the affected nucleus, together with the presence of some abnormally small neurones, and the absence of a recognizable facial nerve. In the case of congenital bilateral abducens paralysis reported by Phillips et al. (1932), no neurones of these nuclei could be identified, and an aberrant fibre tract was present. Un fortunately, examinations of involved muscles in all of these cases have been infrequent and inconclusive, and some proponents of the mesodermal theory (Evans, 1955) point out that the changes in the motor nuclei could be secondary to a disorder in the peripheral field of the involved neurones early in embryogenesis.

Experimental neuroembryology also gives some support to the theory of a primary central dysplasia. In both amphibian and chick embryos, limb buds and their associated muscles develop normally to a point in spite of failure of innervation to reach the limb; this has been demonstrated in the chick embryo by grafting the developing limb bud to an aneural area such as the coelomic cavity before it receives its normal innervation, and in the frog embryo by removal of the lower spinal cord (Hamburger, 1939). While the formation, initial differen tiation, and growth of muscle occurs without in nervation, it is necessary for the final differentiationd and the maintenance of the embryonic muscle? without innervation differentiation arrests at the myotubal stage and fascicle formation is thought nog to occur (Zelená, 1962). Not only does an arrest of final differentiation occur, but after a period of time the developing muscle disintegrates and under goes phagocytosis and fatty replacement (Eastlick and Wortham, 1947). Thus absence of facial muscle alone cannot be used as evidence in support of the mesodermal theory, as has been suggested be Richards (1953).

\section{CONCLUSIONS}

We regard neither theory as proven on the basis of the available evidence, and must admit that the present case fails to clear completely the murky waters of aetiology. However, we feel that there is indirect evidence that peripheral factors were the major ones in this case, in spite of the pathological findings in the brain. The changes in the brain-stem are believed to be secondary to the hemihypoplasia of the cerebellum, and are characteristic of those found in such conditions (Dow and Moruzzi, 1958). Although a case has been recorded in which dysplasia of the auditory, vestibular, and spinal fifth cranial nerve nuclei was associated with such a cerebellar defect (Rubenstein and Freeman, 1940), we cannot find an instance in which the motor 
cranial nerves or their muscles have been involved. We feel that the central nervous system pathology in our case is fortuitous and unrelated to the muscular defect. The facial nuclei appeared normal in every way. The facial nerves were normal in the brain-stem, subarachnoid space, and within the temporal bone. Moreover, apparently normal neural elements were seen passing through the parotid gland and were in close opposition to both the preserved facial muscle and to the areas of presumed adipose replacement. Finally, there was suggestive evidence of the formation of muscle fascicles even in the latter areas, which would imply that innervation was present, as final differentiation of muscle is not believed to occur in its absence (Zelená, 1962).

On the other hand, it can be objected that the muscle findings are not characteristic of a myopathy. Certainly extreme variation in fibre size, sarcolemmal proliferation, and central migration of

A nuclei is not prominent. Degenerating or regenerating muscle fibres and those undergoing phagocytosis are also absent. All of these changes have been described in the probably related condition of arthrogryposis multiplex congenita when it is due to congenital muscular dystrophy (Banker, Victor, and Adams, 1957). However, it is not established that

I these changes, usually associated with a progressive myopathy, would of necessity be present if the primary defect were a failure of proper formation of muscle. Although we think that our findings are compatible with a primary failure of muscle formation, histological standards by which to diagnose such a failure are obscure. As it has been shown experimentally in the chick embryo that muscle breakdown and its adipose replacement is present at term if innervation fails to reach the developing muscle (Eastlick and Wortham, 1947), it seems likely that the end result of such a failure of innervation would be histologically similar, particularly if final differentiation of muscle had failed to occur. Thus, we doubt if histological examination of only the 'end stage muscle' found in the face of the mature neonate or older child could in itself conclusively prove either theory of pathogenesis.

However, the presence of morphologically normal elements of the facial nerve, from the facial nucleus at least to the parotid gland and probably into the facial muscles, suggests to us that a primary failure of formation of the facial musculature produced the Moebius syndrome in this case. Although we believe

1 that the Moebius syndrome in our case probably was due to a primary dysplasia of the facial muscles, we think it likely that in other instances (Heubner, 1900; Spatz and Ullrich, 1931) it was due to a primary neuronal dysplasia. Thus we regard the Moebius syndrome as 'bulbar arthrogryposis', if such a tortured phrase is permissible, in that it can have more than one aetiology and can involve the brain-stem and/or musculature derived from the branchial arches in much the same way as arthrogryposis can involve the spinal cord and/or musculature derived from the somites. This conclusion must be regarded as tentative. While some might agree with Richter (1960) that pathological changes of a developmental nature must be interpreted as primary to the structure in which they are found, we would agree with Hamburger and Levi-Montalcini (1950) that the incompletely understood and extremely complex relationships between nervous structures and their peripheral fields in the developing embryo are reciprocal, and that much caution must be exercised in assigning primacy to one or the other site.

\section{SUMMARY}

A patient with the Moebius syndrome is described and the necropsy findings are presented. We believe this to be the only reported case in which the brain, facial nerves, and involved muscles have all been examined. The literature of the subject is reviewed, with particular attention to the few reported necropsies and the pertinent findings of experimental embryology. It has been postulated that the syndrome is due to a dysplasia of either the involved muscles or the motor nuclei of the brain-stem. We think that the present case is due to a dysplasia of the facial muscles, but, by analogy with arthrogryposis, it is considered probable that both myopathic and neurogenic forms of the syndrome exist.

This study was supported in part by U.S.P.H.S. grant number NB-05274-04 of the National Institute of Neurological Diseases and Blindness (Dr. Pitner) and by a grant from the Hoffmann-LaRoche Company (Dr. Edwards). The authors are indebted to Dr. Warren Johnson, Pathologist to the Clinic for Muscle Diseases, St. Jude's Children's Hospital, Memphis, for reviewing the temporal bone and facial muscle slides. Dr. Hans Zellweger, State University of Iowa, kindly translated the German articles. Dr. Robert A. Utterback, Professor of Neurology, University of Tennessee, Dr. Maurice Van Allen, Associate Professor of Neurology, State University of Iowa, and Dr. Viktor Hamburger, Professor of Zoology, Washington University, reviewed the manuscript and made helpful suggestions, thus being largely responsible for any of the merit, but none of the defects, of this study.

\section{REFERENCES}

Adams, R. D., Denny-Brown, D., and Pearson, C. M. (1962). Diseases of Muscle, 2nd ed., pp. 301-304. Hoeber, New York.

Banker, B. Q., Victor, M., and Adams, R. D. (1957). Arthrogryposis multiplex due to congenital muscular dystrophy. Brain, 80 319-334. 
Bing, R. (1902). Ueber angeborne Muskeldefecte. Virchows Arch. path. Anat., 170, 175-228.

Bonnevie, K. (1934). Embryological analysis of gene manifestation in Little and Bagg's abnormal mouse tribe. J. exp. Zool., 67, 443-520.

Dow, R. S., and Moruzzi, G. (1958). The Physiology and Pathology of the Cerebellum, pp. 416-444. University of Minnesota Press, Minneapolis.

Dunnebacke, T. H. (1953). The effects of the extirpation of the superior oblique muscle on the trochlear nucleus in the chick embryo. J. comp. Neurol., 98, 155-175.

Eastlick, H. L., and Wortham, R. A. (1947). Studies on transplanted embryonic limbs of the chick. III. The replacement of muscle by 'adipose tissue'. J. Morph, 80, 369-389.

Evans, P. R. (1955). Nuclear agenesis. Möbius' syndrome: the congenital facial diplegia syndrome. Arch. Dis. Childh., 30, 237-243.

Fényes, I. (1937). Zur Frage der Entstehung von angeborenen Beweglichkeitsstörungen im Gehirnnervenbereich. Ein klinischanatomischer Beitrag. Arch. Psychiat. Nervenkr., 106, 296-311.

Graefe, A. (1880). Handbuch der gesammten Augenheilkunde, ed. A. Graéfe and T. Saemisch, vol. 6, p. 60. Engelmann, Leipzig.

Graham, P. J. (1964). Congenital flaccid bulbar palsy. Brit. med. J., 2, 26-28.

Grüneberg, H. (1952). The Genetics of the Mouse, 2nd ed., pp. 147-162. Nijhoff, The Hague.

Hamburger, V. (1939). The development and innervation of transplanted limb primordia of chick embryos. J. exp. Zool., 80, 347-389.

- and Levi-Montalcini, R. (1950). Some aspects of Neuroembryology. In Genetic Neurology, edited by P. Weiss, pp. 128-160. University of Chicago Press, Chicago.

Henderson, J. L. (1939). The congenital facial diplegia syndrome: clinical features, pathology, and aetiology. A review of sixtyone cases. Brain, 62, 381-403.

Heubner, O. (1900). Ueber angeborenen Kernmangel (infantiler Kernschwund, Moebius). Charité-Ann., 25, 211-243.

Lennon, M. B. (1910). Congenital defects of the muscles of the face and eyes. Infantiler Kernschwund of Moebius. Report of three cases. Calif. State J. Med., 8, 115-117.

Marfan, A.-B., and Armand-Delille (1901). Paralysie faciale congénitale du côté droit. Agénésie de la portion périphérique du nerf facial avec agénésie des diverses parties constituantes de l'oreille du même côté. Atrophie probablement secondaire de la racine et du noyau du facial. Bull. Soc. Méd. Hôp. Paris, 3rd ser., 18, 1007-1014.
Möbius, P. J, (1888), Ueber angeborenen doppelseitige Abducens- $Z$ Facialis-Lähmung. Münch. med. Wschr., 35, 91-94.

- (1892). Ueber infantilen Kernschwund. Ibid., 39, 17-21, 41-43, 55-58.

Neurath, R. (1907). Zur Frage der angeborenen Funktionsdefecte im $\subseteq$ Gebiete der motorischen Hirnnerven. Ibid., 54, 1224-1228.

Parker, N. (1963). Dystrophia myotonica presenting as congenital facial diplegia. Med. J. Aust., 2, 939-944.

Phillips, W. H., Dirion, J. K., and Graves, G. O. (1932). Congenital bilateral palsy of the abducens. Arch. Ophthal. (Chic.), 8, $\frac{\bigcirc}{\supset}$ 355-364.

Plott, D. (1964). Congenital laryngeal-abductor paralysis due to nucleus ambiguus dysgenesis in three brothers. New Engl. J. Med., 271, 593-597.

Rainy, H., and Fowler, J. S. (1903). Congenital facial diplegia due to $\stackrel{\vec{S}}{\vec{S}}$ nuclear lesion. Rev. Neurol. Psychiat., 1, 149-155.

Reed, H., and Grant, W. (1957). Möbius's syndrome. Brit. J. Ophthal.,

41, 731-740.
Richards, R. N. (1953). The Möbius syndrome. J. Bone Jt. Surg. $\frac{\overline{\bar{S}}}{\bar{T}}$ (Amer), 35, 437-444.

Richter, R. B. (1958). Congenital hypoplasia of the facial nucleus. J. Neuropath. exp. Neurol., 17, 520.

- (1960). Unilateral congenital hypoplasia of the facial nucleus. की Ibid., 19, 33-41.

Riggs, E. H. (1958). Congenital hypoplasia of the facial nucleus. $\vec{\circ}$ (Discussion). Ibid., 17, 520

Rubinstein, H. S., and Freeman, W. (1940). Cerebehar agenesis. J. $\vec{C}$ nerv. ment. Dis., 92, 489-502.

Spatz, H., and Ullrich, O. (1931). Klinischer und anatomischer Beitrag zu den angeborenen Beweglichkeitsdefeckten im Hirnnervenbereich. $Z$. Kinderheilk, 51, 579-597.

Sprof kin, B. E., and Hillman, J. W. (1956), Moebius's syndrome- iN congenital oculofacial paralysis. Neurology (Minneap.), 6, $50-54$.

Ullrich, O. (1949). Turner's syndrome and Status Bonnevie-Ullrieg. Amer. J. hum. Genet., 1, 179-202.

Van Allen, M. W., and Blodi, F. C. (1960). Neurologic aspects of the Möbius syndrome. Neurology (Minneap.), 10, 249-259.

Wallis, P. G. (1960). Creatinuria in Möbius' syndrome. Arch. Dis. Childh., 35, 393-395.

Yasuna, J. M., and Schlezinger, N. S. (1955). Congenital bilateral abducens: facial paralysis (Möbius syndrome). Arch. Ophth. (Chic.), 54, 137-139.

Zelená, J. (1962). The effect of denervation on muscle developmen.

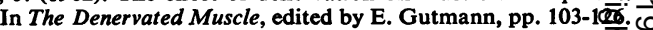
Czechoslovak Academy of Sciences, Prague. 